\title{
A curve model for association of serum homocysteine with carotid artery hemodynamics
}

\author{
Zewei $\mathrm{Wu}^{1}$, Yufeng Wen ${ }^{1 *}$, Mengxue Liu${ }^{1}$, Haibo $\mathrm{Li}^{1}$, Yu Zhu${ }^{1}$, Huiping Zhang ${ }^{2}$ \\ and Tiantian Ren ${ }^{2}$ \\ ${ }^{1}$ School of Public Health, Wannan Medical College, Wuhu City, Anhui Province 241002, ${ }^{2}$ Department of Medical Ultrasonics, \\ Ma'anshan People's Hospital, Ma'anshan City, Anhui Province 243000, PR China
}

*For correspondence: Email: wyf@wnmc.edu.cn,wyf2015w@sina.com; Tel/Fax: +86-0553-3932059

\begin{abstract}
Purpose: To investigate the correlation between carotid artery hemodynamics and serum homocysteine.

Methods: A total of 894 participants made up of 439 male $(49.11 \%)$ and 455 female (50.89 \%) from Ma'anshan, China, enrolled in the cross-sectional study. Data collection included demographics, blood sample and carotid ultrasonography. Piecewise linear regression analysis was used to analyze the relationship between serum homocysteine and carotid artery hemodynamics.

Results: Homocysteine (Hcy) levels were divided into four groups by quartiles. The populations of the groups were 226, 220, 222, 226; and their mean ages were 56.52 $\pm 10.49,62.27 \pm 10.06,63.42 \pm 9.81$ and $65.38 \pm 10.56$ years, respectively. After adjustment for blood biochemical and demographics factors, U-shaped and S-shaped curves were as observed between Hcy and carotid artery hemodynamics. The adjusted regression analysis showed that the threshold values of Hcy with end diastolic velocity (EDV) of right common carotid artery (CCA) were 12.50 and 19.00, while for the EDV of right internal carotid artery (ICA), the values were 11.50 and 22.00. U-shaped curves were observed between Hcy and peak systolic velocity (PSV) of left CCA, EDV of left CCA, PSV of left ICA and EDV of left ICA. The threshold values of Hcy with PSV of left CCA, EDV of left CCA, PSV of left ICA and EDV of left ICA were 14.00, 14.00, 14.00 and 13.50, respectively.

Conclusion: These results indicate that a significant correlation exists between homocysteine at different concentrations and carotid artery hemodynamics.
\end{abstract}

Keywords: Homocysteine, Hemodynamics, End diastolic velocity, Peak systolic velocity

Tropical Journal of Pharmaceutical Research is indexed by Science Citation Index (SciSearch), Scopus, International Pharmaceutical Abstract, Chemical Abstracts, Embase, Index Copernicus, EBSCO, African Index Medicus, JournalSeek, Journal Citation Reports/Science Edition, Directory of Open Access Journals (DOAJ), African Journal Online, Bioline International, Open-J-Gate and Pharmacy Abstracts

\section{INTRODUCTION}

Cardiovascular disease (CVD) is a main cause of death across the globe, resulting in more than 17.3 million deaths in 2013 , and is projected to result in the death of more than 23.6 million people by 2030 [1]. A recent study had revealed that $\mathrm{Hcy}$ is an independent risk and predictive factor for CVD [2]. Hcy accelerates vascular endothelial injury, low-density lipoprotein oxidation and vascular smooth muscle cells proliferation [3-5]. Carotid ultrasonic examination for evaluation of atherosclerosis (AS) mainly involves hemodynamics, intima-media thickness (IMT) and plaque size [6]. And IMT is negatively correlated with wall shear stress (WSS) in the common carotid artery (CCA) [7]. In addition, peak systolic velocity (PSV) ratio of CCA was positively associated with high-grade common carotid stenosis [8]. 
A recent study showed that Hcy was positively correlated with carotid intima-media thickness (IMT) in adolescent hypertension [9]. In addition, results of a cross-sectional study showed that increased Hcy was associated with advanced carotid plaque in males [10]. Despite the fact that Hcy and hemodynamics are associated with IMT and carotid plaque, their exact inter-relationship is yet to be investigated. A recent research found that pulsatility index (PI) was correlated with Hcy in patients with essential hypertension [11].

However, the relationship between Hcy and other hemodynamic parameters such as PSV and end diastolic velocity (EDV) is not yet understood. The current research is a cross-sectional study to investigate whether there is an association between serum Hcy and PSV and EDV of carotid artery.

\section{METHODS}

\section{Patients}

A total of 894 patients were recruited from December 2013 to June 2014 in Ma'anshan People's Hospital, China. Inclusion criteria were: (1) patients aged from 30 to 80 ; (2) patients without history of intervention therapy for carotid artery stenosis; (3) patients without history of stroke, cancer or severe infection; and (4) patients without rheumatic heart disease, hypertensive heart disease, or congenital heart disease. This study was approved by the Ethical Committee of Ma'anshan People's Hospital (approval no. 2014002) and followed the guidelines of the World Medical Association Declaration of Helsinki [12].

\section{Survey questionnaire}

The questionnaire contained social-demographic characteristics (e.g., sex, age, education level, occupation, etc); behavior characteristics (smoking status, drinking status and physical exercise), and history of disease (stroke, coronary heart disease, hypertension and diabetes). Face-to-face interview was used for the survey.

Physical examination included height, weight and blood pressure. In blood pressure measurement, all participants rested for $15 \mathrm{~min}$ in quiet environments and were tested with mercury sphygmomanometer (Yuyue, China). Height and weight measurements were carried out by electronic height and weight instrument (HGM300, Tian Jinggang, China).
Hypertension was defined as either taking antihypertensive drugs or systolic blood pressure $(\mathrm{SBP}) \geq 140 \mathrm{mmHg}$ and/or diastolic blood pressure $(D B P) \geq 90 \mathrm{mmHg}$. Diabetes status was defined as either using anti-diabetic drugs or $\mathrm{FPG}>7.1 \mathrm{mmol} / \mathrm{L}$. Frequent smoker was defined as smoking more than 1 cigarette/day or never. Drinking was defined as taking more than 1 drink /week, or never, and physical exercise was defined as exercising 3-7 times/week, or never.

\section{Biochemical assays}

Venous blood specimens were collected in the morning from the patients after an overnight fast. All samples were stored at $-70{ }^{\circ} \mathrm{C}$ until biochemical assay. Serum total cholesterol (TC), triglyceride (TG), high-density lipoprotein (HDL), fasting plasma glucose (FPG) and Hcy were determined with automated biochemical analyzer (DPP-800, Roche, Germany) in Ma'anshan People's Hospital. All data from laboratory assays and Doppler ultrasound were collected on the same day.

\section{Carotid ultrasonography}

Patients were made to take a $10-\mathrm{min}$ break to stabilize blood pressure and heart rate prior to ultrasound examination in supine position with the head tilted to the contralateral side. The proximal and distal walls of the left and right CCA and internal carotid artery (ICA) were measured for PSV and EDV with 5-13 MHz linear-array probes (Aloka-a7 and Aloka-a10, Japan; PhilipsIU22, America).

\section{Statistical analysis}

The study objects were segmented into four groups by quartiles $\left(P_{25}, P_{50}, P_{75}\right.$ and $\left.P_{100}\right)$ of Hcy. TG was log-transformed because its skewed distribution data, and was expressed as a median $\left(\mathrm{P}_{25}, \mathrm{P}_{75}\right)$. Other continuous variables are expressed as mean \pm SD. Categorical variables were presented as percentage. Chisquare test for categorical variables and ANOVA test for continuous variables were used to compare the characteristics in different Hcy levels. Generalized smoothing splines were used to evaluate relationship between serum Hcy and carotid artery hemodynamics. In order to investigate the threshold effect of Hcy on hemodynamics, piece-wise linear regression model was used. Two-side value of $p<0.05$ was considered statistically significant. $\mathrm{R}$ software, version 3.0.1 (http://www.R-project.org) was used for statistical analysis. 


\section{RESULTS}

\section{Characteristics of patients}

The mean age of participants was $61.89 \pm 10.75$ years, and the mean Hcy was $13.28 \pm 7.51$ $\mu \mathrm{mol} / \mathrm{L}$. Hcy was significantly higher in the male patients than in the female patients $(14.57 \pm 7.64$ versus $12.04 \pm 7.17 \mu \mathrm{mol} / \mathrm{L} ; p<0.001)$.

Table 1 shows baseline information by quartiles of Hcy. There was correlation between increased serum Hcy level and age, gender, SBP, smoking, drinking and HDL. Increased prevalence of carotid artery disease and hypertension were related to the raised quartiles of Hcy.

\section{Relationship between Hcy and hemody- namics by piecewise linear regression}

Figure 1 and Table 2 show that after adjustment for age, BMI, SBP, DBP, HDL, FPG, TC, TG, carotid artery disease, smoking status and drinking status, S-shaped curve was found between Hcy and EDV of right CCA, and between Hcy and EDV of right ICA by generalized smoothing splines. The threshold values of Hcy with EDV of right CCA were 12.50 and 19.00; with EDV of right ICA the threshold values were 11.50 and 22.00. U-shaped curve was observed between Hcy and PSV of left CCA; and between Hcy and EDV of left CCA. Ushaped curve was also observed between Hcy and PSV of left ICA and between Hcy and EDV of left ICA. The threshold values of Hcy with PSV of left CCA, EDV of left CCA, PSV of left ICA, and EDV of left ICA were 14.00, 14.00, 14.00 and 13.50 , respectively.

\section{DISCUSSION}

The findings of this research are consistent with the results of Memisogullari et al [13], and demonstrate that $\mathrm{Hcy}$ is associated with hemodynamics. Factor such as blood pressure is reported to be related to hemodynamics [14]. After adjustment for potential confounders, the relationship between $\mathrm{Hcy}$ and hemodynamics was a curve pattern, and the threshold values of Hcy were diverse in different parts of the carotid artery. However, results obtained by Memisogullari et al [13] in a previous study on correlation between Hcy and hemodynamics in ophthalmic artery of highway toll collectors revealed a linear pattern, in which high Hcy level was related to the decreased EDV and RI. However, Memisogullari et al based their study on the ophthalmic artery and only 22 toll subjects, while the current study focused on the carotid artery, and used a far greater number of subjects. These differences may be responsible for the disparity in the relationships between Hcy and hemodynamics. Further studies are nonetheless needed to unravel other likely causes of the disparity.

Another study reported that endothelial dysfunction and apoptosis could result in AS [15]. Endothelial cells exert an influence on hemodynamics [16]. Hcy may enhance the oxidation of low density lipoprotein (LDL) [3], which promotes injury of endothelial cells [17]. Furthermore, Hcy increases the accumulation of the endogenous nitric oxide synthase inhibitor asymmetric dimethylarginine, and is positively

Table 1: Comparison of subjects' baseline information by quartiles of Hcy

\begin{tabular}{|c|c|c|c|c|c|c|}
\hline \multirow[b]{2}{*}{ Item } & \multicolumn{4}{|c|}{ Hcy Quartiles } & \multirow[b]{2}{*}{$F / X^{2}$} & \multirow[b]{2}{*}{$\begin{array}{c}P \\
\text {-value }\end{array}$} \\
\hline & $\begin{array}{c}\text { Quartile 1 } \\
(\leq 8.90) \\
\mathrm{N}=226 \\
\end{array}$ & $\begin{array}{c}\text { Quartile 2 } \\
\text { (8.90-11.75) } \\
\mathrm{N}=220\end{array}$ & $\begin{array}{c}\text { Quartile 3 } \\
(11.75-15.40) \\
\mathrm{N}=222\end{array}$ & $\begin{array}{c}\text { Quartile } 4 \\
(>15.40) \\
N=226\end{array}$ & & \\
\hline $\begin{array}{l}\text { Age } \\
\text { year }\end{array}$ & $56.52 \pm 10.49$ & $62.27 \pm 10.06$ & $63.42 \pm 9.81$ & $65.38 \pm 10.56$ & 31.19 & $<0.001$ \\
\hline $\begin{array}{l}\text { Sex: Male } \\
\text { Female }\end{array}$ & $\begin{array}{c}78(17.77) \\
148(32.53)\end{array}$ & $\begin{array}{c}98(22.32) \\
122(26.81)\end{array}$ & $\begin{array}{l}118(26.88) \\
104(22.86)\end{array}$ & $\begin{array}{c}145(33.03) \\
81(17.80)\end{array}$ & 43.03 & $<0.001$ \\
\hline BMI kg/m² & $24.23 \pm 4.21$ & $24.45 \pm 2.96$ & $24.18 \pm 2.97$ & $23.97 \pm 3.15$ & 0.70 & 0.553 \\
\hline SBP mmHg & $131.85 \pm 15.52$ & $136.49 \pm 17.05$ & $135.23 \pm 18.12$ & $137.14 \pm 17.91$ & 4.10 & 0.007 \\
\hline DBP mmHg & $80.62 \pm 10.81$ & $81.65 \pm 11.14$ & $80.43 \pm 10.17$ & $79.82 \pm 11.43$ & 1.00 & 0.393 \\
\hline CAD & $65(12.36)$ & $135(25.67)$ & $152(28.90)$ & $174(33.08)$ & 128.25 & $<0.001$ \\
\hline HTN & $118(20.24)$ & $164(28.13)$ & $151(25.90)$ & 150 (25.73) & 26.53 & $<0.001$ \\
\hline Diabetes & $92(30.87)$ & $67(22.48)$ & $66(22.15)$ & $73(24.50)$ & 7.48 & 0.058 \\
\hline Smoking & $47(18.15)$ & 57 (22.01) & $69(26.64)$ & 86 (33.02) & 18.56 & $<0.001$ \\
\hline Drinking & $34(18.68)$ & $44(24.18)$ & $44(24.18)$ & 60 (32.67) & 9.64 & 0.022 \\
\hline $\mathrm{TC} \mathrm{mmol} / \mathrm{L}$ & $4.28 \pm 1.50$ & $4.63 \pm 1.98$ & $4.35 \pm 1.45$ & $4.37 \pm 1.56$ & 1.97 & 0.117 \\
\hline $\mathrm{TG}^{*} \mathrm{mmol} / \mathrm{L}$ & $1.24(0.95,1.81)$ & $1.26(0.94,1.81)$ & $1.31(0.95,1.76)$ & $1.26(0.93,1.74)$ & 0.86 & 0.462 \\
\hline HDL mmol/L & $1.29 \pm 0.34$ & $1.21 \pm 0.31$ & $1.17 \pm 0.27$ & $1.11 \pm 0.31$ & 13.77 & $<0.001$ \\
\hline FPG mmol/L & $6.72 \pm 3.45$ & $6.06 \pm 2.76$ & $6.42 \pm 5.46$ & $5.95 \pm 2.61$ & 1.89 & 0.130 \\
\hline
\end{tabular}

${ }^{\star} P$-values obtained by using the log transformation. Data were expressed as mean $\pm S D$., median $\left(P_{25}, P_{75}\right)$, or $n$ (\%), $B M I=$ body mass index, $C A D=$ Carotid artery disease, $H T N=$ hypertension 

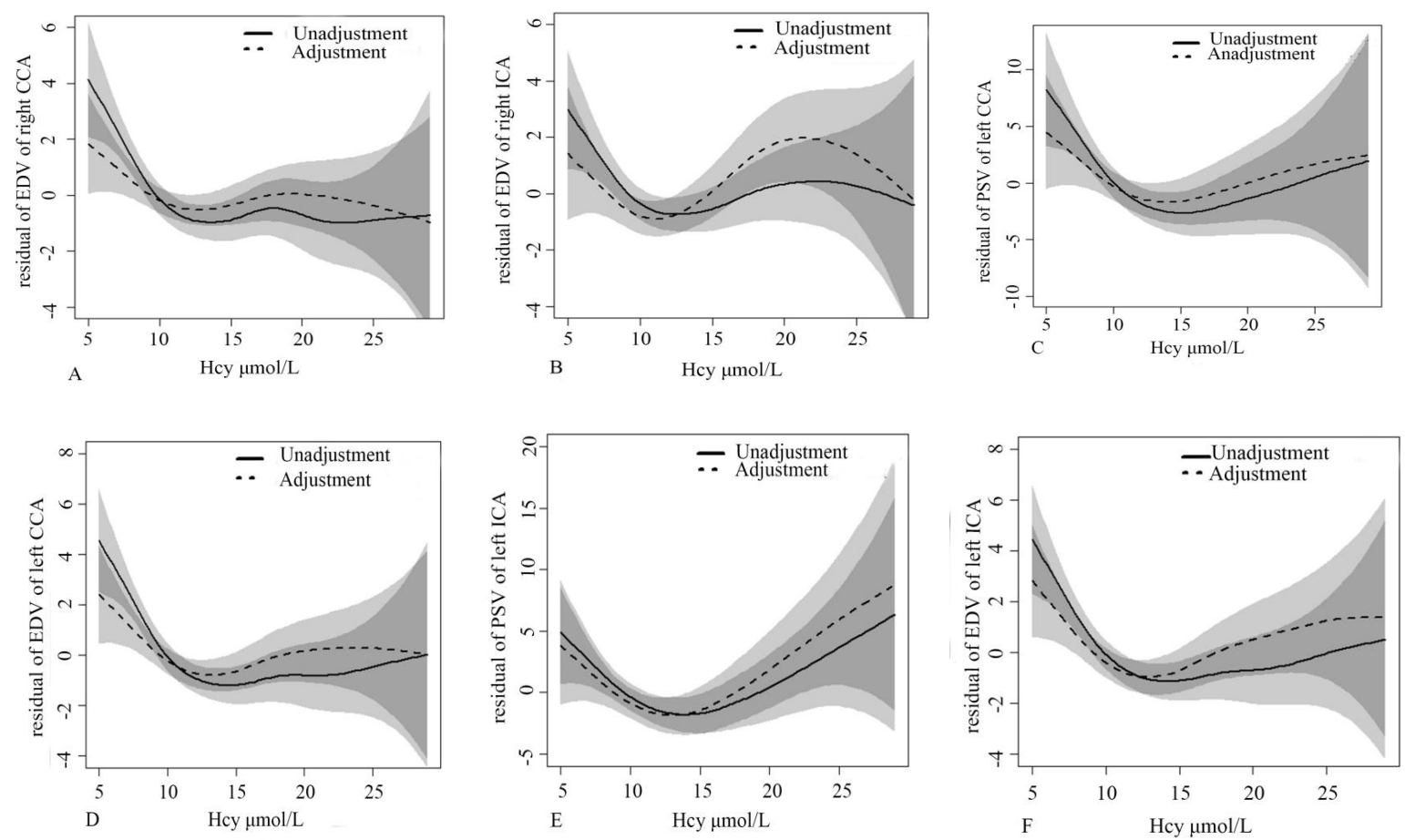

Figure 1: Relationship between Hcy and hemodynamics, using generalized smoothing splines. Solid line: without adjustment; dotted line: adjustment for age, BMI, SBP, DBP, HDL, FPG, TC, TG, carotid artery disease, smoking and drinking status.. A: Hcy with EDV of right CCA; B: Hcy with EDV of right ICA; C: Hcy with PSV of left CCA; D: Hcy with EDV of left CCA; E: Hcy with PSV of left ICA; F: Hcy with EDV of left ICA

Table 2: A piecewise linear regression model of the relationship between Hcy and hemodynamics (adjustment for age, BMI, SBP, DBP, HDL, FPG, TC, TG, carotid artery disease, smoking and drinking status)

\begin{tabular}{lccccccc}
\hline Ultrasound & $\begin{array}{c}\text { Hcy } \\
\text { parameter }\end{array}$ & \multicolumn{3}{c}{ Unadjusted } & \multicolumn{3}{c}{ Adjusted } \\
\cline { 2 - 8 } & $\leq 12.50$ & -0.75 & 0.16 & $<0.001$ & -0.39 & 0.18 & 0.036 \\
& $12.50 \sim$ & 0.24 & 0.21 & 0.253 & 0.10 & 0.23 & 0.669 \\
& $>19.00$ & 0.20 & 0.30 & 0.513 & -0.39 & 0.32 & 0.220 \\
EDV of RCCA & $\leq 11.5$ & -0.93 & 0.22 & $<0.001$ & -0.51 & 0.25 & 0.042 \\
& $11.50 \sim$ & 0.04 & 0.16 & 0.813 & 0.29 & 0.18 & 0.110 \\
& $>22.00$ & -0.31 & 0.60 & 0.612 & -0.20 & 0.70 & 0.781 \\
PSV of LCCA & $\leq 14.00$ & -1.21 & 0.36 & 0.001 & -0.81 & 0.40 & 0.044 \\
& $>14.00$ & 0.47 & 0.36 & 0.188 & 0.43 & 0.41 & 0.301 \\
EDV of LCCA & $\leq 14.00$ & -0.61 & 0.12 & $<0.001$ & -0.35 & 0.13 & 0.007 \\
& $>14.00$ & 0.11 & 0.13 & 0.372 & 0.10 & 0.13 & 0.673 \\
PSV of LICA & $\leq 14.00$ & -0.84 & 0.30 & 0.006 & -0.76 & 0.35 & 0.031 \\
& $>14.00$ & 0.64 & 0.36 & 0.077 & 0.98 & 0.38 & 0.008 \\
EDV of LICA & $\leq 13.50$ & -0.61 & 0.14 & $<0.001$ & -0.40 & 0.15 & 0.005 \\
& $>13.50$ & 0.10 & 0.13 & 0.446 & 0.21 & 0.14 & 0.141 \\
\hline
\end{tabular}

$R C C A=$ right common carotid artery, RICA = right internal carotid artery, LCCA = left common carotid artery, $L I C A=$ left internal carotid artery

related to flow-mediated vasodilatation [18]. Coronary hemodynamics are affected by nitric oxide (NO) due to vasodilation and inhibition of platelet adhesion and aggregation [19]. It has been reported that Hcy level was related to polymorphism of endothelial NO gene intron [20].

Although the exact mechanism involved in the correlation between Hcy and hemodynamics is not clear, several studies showed that Hcy had a positive correlation with IMT [9]. An inverse relationship has been demonstrated between
IMT and mean cerebral blood flow velocity (mCBFV), with decreased CBFV corresponding to elevated IMT [21]. In addition, Mohan et al [22] suggested that exposure to Hcy could induce platelet activation and hypercoagulability. Since platelet activating factor can reduce reducing coronary blood flow [23], these results indicate that Hcy may affect hemodynamics.

Interestingly, a curve relationship was found between Hcy and hemodynamics in the present study. The reason for the curve model is not 
clear, but it might be related to hyperhomocysteinaemia (HHcy). HHcy is defined as $\mathrm{Hcy}>15 \mu \mathrm{mol} / \mathrm{L}$ [24]. The results obtained in this study showed that at Hcy levels below 15 $\mu \mathrm{mol} / \mathrm{L}$, increased Hcy was related to decreased hemodynamics, while Hcy levels higher than 15 $\mu \mathrm{mol} / \mathrm{L}$ were positively correlated with hemodynamics. This is due to the fact that Hcy is responsible for the hypercoagulability status of blood [22], and so it can reduce blood flow velocity. Hemodynamics is positively associated with carotid stenosis and carotid stenosis could result from HHcy [25]. Therefore, higher Hcy levels might promote increases in hemodynamics. Our results further showed that at Hcy level of about $14 \mu \mathrm{mol} / \mathrm{L}$, the effect on hemodynamics was different. Based on this, it can be hypothesized that the threshold value of HHcy should be close to $14 \mu \mathrm{mol} / \mathrm{L}$.

\section{Limitations of the study}

This study has two limitations. First, the mechanism involved in the effect of Hcy on hemodynamics is still not clear; further research is needed to establish this in an animal model or cell culture. Second, blood viscosity was not measured in this study.

\section{CONCLUSION}

The findings obtained in this study demonstrate a significant correlation between homocysteine (at different concentrations) and carotid artery hemodynamics. They also confirm the role of Hcy and hemodynamics in atherogenesis as well as provide evidence for the prevention of atherosclerosis.

\section{DECLARATIONS}

\section{Acknowledgement}

The authors would like to thank all the staff of the Department of Medical Ultrasonics, Ma'anshan People's Hospital for technical assistance, as well as the participants for their co-operation during data collection.

\section{Conflict of Interest}

No conflict of interest associated with this work.

\section{Contribution of Authors}

The authors declare that this work was done by the authors named in this article and all liabilities pertaining to claims relating to the content of this article will be borne by them.

\section{Open Access}

This is an Open Access article that uses a funding model which does not charge readers or their institutions for access and distributed under the terms of the Creative Commons Attribution License (http://creativecommons.org/ licenses/by/ 4.0) and the Budapest Open Access Initiative (http://www.budapestopena ccessinitiative.org/read), which permit unrestricted use, distribution, and reproduction in any medium, provided the original work is properly credited.

\section{REFERENCES}

1. Mozaffarian D, Benjamin EJ, Go AS, Arnett DK, Blaha MJ, Cushman M, Das SR, de Ferranti S, Despres JP, Fullerton $\mathrm{HJ}$ et al. Heart Disease and Stroke Statistics2016 Update: A Report From the American Heart Association. Circulation 2016; 133(4): e38-360.

2. Ebesunun MO, Obajobi EO. Elevated plasma homocysteine in type 2 diabetes mellitus: a risk factor for cardiovascular diseases. Pan Afr Med J 2012; 12 : 48.

3. Shirpoor A, Salami S, Khadem Ansari MH, Ilkhanizadeh $B$, Abdollahzadeh $N$. Ethanol promotes rat aortic vascular smooth muscle cell proliferation via increase of homocysteine and oxidized-low-density lipoprotein. J Cardiol 2013; 62(6): 374-378.

4. Zhu JH, Chen JZ, Wang XX, Xie XD, Sun J, Zhang FR. Homocysteine accelerates senescence and reduces proliferation of endothelial progenitor cells. J Mol Cell Cardiol 2006; 40(5): 648-652.

5. Sim WC, Han I, Lee W, Choi YJ, Lee KY, Kim DG, Jung $\mathrm{SH}$, Oh SH, Lee BH. Inhibition of homocysteine-induced endoplasmic reticulum stress and endothelial cell damage by l-serine and glycine. Toxicol In Vitro 2016; 34: 138-145.

6. Lee W. General principles of carotid Doppler ultrasonography. Ultrasonography 2014; 33(1): 11-17.

7. Augst $A D$, Ariff $B, M c G$ Thom $S A, X u X Y$, Hughes $A D$. Analysis of complex flow and the relationship between blood pressure, wall shear stress, and intima-media thickness in the human carotid artery. Am J Physiol Heart Circ Physiol 2007; 293(2): H1031-1037.

8. Pisimisis GT, Katsavelis D, Mandviwala T, Barshes NR, Kougias $P$. Common carotid artery peak systolic velocity ratio predicts high-grade common carotid stenosis. $J$ Vasc Surg 2015; 62(4): 951-957.

9. Lengyel S, Katona E, Zatik J, Molnár C, Paragh G, Fülesdi B, Páll D. The impact of serum homocysteine on intima-media thickness in normotensive, white-coat and sustained hypertensive adolescents. Blood Press 2012; 21(1): 39-44.

10. Yang $X$, Zhou Y, Liu C, Gao X, Wang A, Guo Y, Li W, Zhao $X$, Liang $W$. Homocysteine and carotid plaque 
stability: a cross-sectional study in Chinese adults. PloS One 2014; 9(4): e94935.

11. Jotoku M, Okura T, Miyoshi K, Irita J, Nagao T, Kukida M, Tanino A, Kudo K, Enomoto D, Pei $Z$ et al. Carotid hemodynamics is associated with monocyte count determined by serum homocysteine level in patients with essential hypertension. Clin Exp Hypertens 2015; 37(5): 358-363.

12. World Medical Association. World Medical Association Declaration of Helsinki: ethical principles for medical research involving human subjects (revised October 7 , 2000). HIV Clin Trials 2001; 2(1): 92-95.

13. Memişoğullari R, Yüksel $H$, Coskun A, Yüksel HK, Yazgan $O$, Bilgin $C$. High serum homocysteine levels correlate with a decrease in the blood flow velocity of the ophthalmic artery in highway toll collectors. Tohoku $J$ Exp Med 2007; 212(3): 247-252.

14. Kisser JE, Allen AJ, Katzel LI, Wendell CR, Siegel EL, Lefkowitz D, Waldstein SR. Relations of blood pressure and head injury to regional cerebral blood flow. $J$ Neurol Sci 2016; 365: 9-14.

15. Byfield FJ, Tikku S, Rothblat GH, Gooch KJ, Levitan I. $O x L D L$ increases endothelial stiffness, force generation, and network formation. J Lipid Res 2006; 47(4): 715723.

16. Simmers $M B$, Cole BK, Ogletree $M L$, Chen $Z, X u Y$, Kong $L J$, Mackman $N$, Blackman BR, Wamhoff $B R$. Hemodynamics associated with atrial fibrillation directly alters thrombotic potential of endothelial cells. Thromb Res 2016; 143: 34-39.

17. Chung MJ, Kim SH, Park JW, Lee YJ, Ham SS. Platycodon grandiflorum root attenuates vascular endothelial cell injury by oxidized low-density lipoprotein and prevents high-fat diet-induced dyslipidemia in mice by up-regulating antioxidant proteins. Nutr Res 2012; 32(5): 365-373.
18. Stühlinger MC, Oka RK, Graf EE, Schmölzer I, Upson BM, Kapoor O, Szuba A, Malinow MR, Wascher TC, Pachinger $O$ et al. Endothelial dysfunction induced by hyperhomocyst(e)inemia: role of asymmetric dimethylarginine. Circulation 2003; 108(8): 933-938.

19. Toda N, Toda H. Coronary hemodynamic regulation by nitric oxide in experimental animals: recent advances. Eur J Pharmacol 2011; 667(1-3): 41-49.

20. Jemaa R, Kallel A, Sediri $Y$, Abdessalem S, Mourali MS, Feki M, Mechmeche R, Kaabachi N. Association between endothelial nitric oxide gene intron 4a4b VNTR polymorphism and plasma homocysteine concentrations in Tunisian male patients with myocardial infarction. Nutr Res 2012; 32(5): 342-346.

21. Kwater A, Gasowski J, Grodzicki T. Intima-media thickness of carotid artery and aortic pulse wave velocity as determinants of cerebral blood flow velocity. J Hum Hypertens 2014; 28(6): 384-387.

22. Mohan IV, Jagroop IA, Mikhailidis DP, Stansby GP. Homocysteine activates platelets in vitro. Clin Appl Thromb Hemost 2008; 14(1): 8-18.

23. Kinn JW, Bache RJ. Effect of platelet activation on coronary collateral blood flow. Circulation 1998; 98(14): 1431-1437.

24. Liu J, Wang $Y$, Fan $H$, Miao L, Zhang $H$, Wang G. Hyperhomocysteinaemia is associated with low plasma apolipoprotein Al levels in patients with impaired glucose tolerance. Diab Vasc Dis Res 2015; 12(4): 298301.

25. Alvarez B, Yugueros X, Fernández E, Luccini $F$, Gené $A$, Matas $M$. Relationship between plasma homocysteine and the morphological and immunohistochemical study of carotid plaques in patients with carotid stenosis over 70\%. Ann Vasc Surg 2012; 26(4): 500-505. 